\title{
The formation and operation of modular organization: A case study on Haier's "market-chain" reform
}

\author{
(C) Higher Education Press and Springer-Verlag 2008
}

\begin{abstract}
The concept of modularity can be applied not only to complex product system design, but also to business system interpretation and design. However, the amount of literature on modular organization is much less than that on product modularity. Based upon a case study on Haier's reengineered business-process system after the "market-chain" reform, this paper examines the course of its process decomposition to form a prototype of modular organization, and further analyzes the evolution of the three key factors in the design rules, which make the independent modules interact with others to form a complex system. The study shows that a system will gain strategic flexibility when more business units in service supplying and product manufacturing are treated as modules of the firm. Meanwhile, a system will become more complex when the number and variety of modules increase, which in turn induces the evolution in the process of the modular organization's decomposition and integration.
\end{abstract}

Keywords modularity, decomposition, integration, business processes, evolution

Translated and revised from Guanli Shijie 管理世界(Management World), 2008, (4): 122-139

WANG Fengbin $(\square)$

School of Business, Renmin University of China, Beijing 100872, China

E-mail:wfengbin@ruc.edu.cn

CHEN Gonghai

School of Business, Renmin University of China, Beijing 100872, China

E-mail: gonghaichen@sina.com

LI Donghong

School of Economics and Management, Tsinghua University, Beijing 100084, China

E-mail: lidh@sem.tsinghua.edu.cn 
摘要 模块化思想不仅可用于复杂产品系统的设计, 也可用来解释或指导企业业务 活动的组织。当前有关组织模块化的研究明显弱于产品模块化设计的研究。以海尔 集团 “市场链” 再造前后的内部流程系统作为案例研究对象, 在考察其流程系统由 职能集中或统一走向模块化解构后, 从业务运作过程中拥有自主性的流程模块如何 与相邻的其他子系统互动的角度, 详细分析了有助于实现流程模块化集结的 “设计 规则三要素” 及其演变, 由此探讨了模块化组织模式的形成及运作特点。研究显示, 将提供服务与制造产品的单位一并作为企业业务组织的模块单元, 使整个系统可以 在多样化的模块构成中增强战略柔性。而随着系统构成要素和类别的增多, 系统运 行的复杂性也增大, 从而模块化解构与集结的过程更表现出演化的特点。

关键词 模块化, 解构, 集结, 业务流程, 演化

\section{Introduction}

With the penetration of complexity research from the field of natural science to social economics, modularity has been noticed by more and more scholars in recent years as a solution to growing complexity (Baldwin and Clark, 1997; 2000) or a decomposition method for handling complex system (Zhang, 2003), and it was applied practically to some extent in the fields of computer and automobile (Baldwin and Clark, 2000; Aoki and Ando, 2003; Ji et al., 2004), integrate circuits (Zhu, 2004), mobile phone (Xie, 2004), and urban subway automation control system (Chen et al., 2006). Presently, the researches on modularity mainly focus on product design as well as the organization of new product development and production processes.

However, even if the artifact structure of a product and the task structure of its design processes are isomorphic, whether or not the processes of product design and production are isomorphic in the same way or to the same extent? Whether or not the organization and the operation of service-providing units are structured in the similar way as product modularity? As a whole, the current researches on these issues are not only few in numbers but also limited in scope.

As to the relation between modular products and modular organizations, Sanchez and Mahoney (1996), Schilling and Steensma (2001) argued that the modularity of products led to the modularity of organizational structures. However, Worren et al. (2002) concluded in an empirical study that the relation between modular products and modular organizations was not significantly related. Langlois and Foss (1997) and Langlois (2002) found IBM actually adopted a non-modular, hierarchical organizational structure to manage the production of the IBM/360 Mainframe computer. As explained by Brusoni and Prencipe (2001), accompanying the shifting of the core component in mainframe from vacuum tube to integrated circuits, IBM needed to transform its organizing 
model from "buy" to "make", that is from modular to vertical integrated. Regarding to the underlying divergent and conflicted viewpoints, what theoretical perspective may be useful and valid to explain the relation between modular products and modular organizations?

In this paper, we examine the case of Haier, which started "market-chain" reform at the end of 1998. In the detailed case analysis, we discuss its organizational characteristics after the long-lasting large-scaled reform, including the decomposition of the business processes, the evolving integrated practices, and principles to form a smoothly operated modular organization. This paper consists of the following major elements: the literature review, the introduction to research methodology, the analysis of the case, and lastly the discussion and conclusion. After an inductive analysis, we propose four theoretical propositions, and point out directions for future research.

\section{Literature review and research method}

\subsection{The origin and development of modularity concept}

The thoughts of modularity are originated from Herbert Simon's consideration on complex system in 1960s. Simon (1962) found that complex systems, whatever they were biological systems, physical systems, or social systems, could be divided into some loosely-coupled components/subsystems which had much stronger internal connections than external connections, i.e., nearly decomposed. Furthermore, the subsystem could also be decomposed down to the most basic organizational units even as the system is broken down into many loosely-coupled subsystems. By this way, the former integrated systems are decomposed into nearly decomposed parts, which were termed latterly as "modules". However, the popularity of this modularity concept owes to Baldwin and Clark. Their co-authored paper, Managing in an Age of Modularity, published in Harvard Business Review in 1997, promoted fast diffusion of the modularity concept.

In the 1990s, scholars in several disciplines were attracted by complexity theory and tried to apply the theoretical concepts in complex system theory in the course of business research, and thus put forward a variety of concepts such as "modular systems", "modular products" and "modular organizations". Amongst this clue of research, the first contributors focused their attention on exploring the distinctive features and advantages of the modular organizations. For instance, some researchers found that, different from the vertically integrated, hierarchical organizations, modular organizations could be a pattern of resource allocation to realize the flexible connection of loosely-coupled components (Schilling and 
Steensma, 2001). Modular organizations are composed of semi-and self-disciplined subsystems (modules) which coupled loosely through "visible" design rules, forming as a hybrid mode of organization. It accelerates the endogenous innovation in the level of module because every undertaker of modular units can develop their new modules independently on the condition of no violating the predefined standardized interfaces. And every module may be produced separately by independent suppliers with distinctive specialized competence, thus resulting in "economies of scale" (Langlois, 2002). Meanwhile, the integrators of the whole systems or subsystems, which are responsible for the integration and (re-)configuration of relevant modules, may acquire an "option" advantage from the possible substitution of modules, that is usually called "economies of substitution" (Garud et al., 2003). Since more options or alternatives available with modules continuously innovated, the integrators of the (sub-)systems would gain better chance to cope with the uncertainties in individual modules (Aoki and Ando, 2003). As a result, it brings "strategic flexibility" (Sanchez and Mahoney, 1996) with better-selected modules combining into different configuration.

After the legitimacy of the modular mode was explained and recognized sufficiently, many researchers have shifted their focus to empirical research in recent years. Various studies found that there exists a complicated relation between modular products and modular organizations, and there seems to be no strong evidence supporting the view that modular products would definitely lead to modular organizations. Hoetker (2006) concluded that the empirical papers on this topic were "few in number" and called upon "future studies should define 'modular organizations' carefully according to their context" and so that "greater attention to the multiple facets of organizational modularity should allow clearer, richer insights".

2.2 Feasibility and significance of applying modularity concept in the organization of business activities

Based upon the observation on the design of such modular products as computers (i.e., IBM/360), automobiles, financial products, and the like, Baldwin and Clark (1997) distinguished the "hidden design parameters" within each modules from the "visible design rules" which are open and spread to all participants, and refined "a guide to modularity" which included three factors, "architecture, interfaces and testing standards". After abstracting from the modular product design, they tried to apply the modularity principles to the structuring of "modular organizations". They found that "just as modularity in design boosts innovation in products by freeing designers to experiment, so managers can speed up development cycles for individual modules by splitting the work among 
independent teams, each pursuing a different submodule or different path to improvement."

Moreover, as both the process and outcome of system decomposition and integration, modularity concept has been widely applied in the research of networked connection between product assemblers and component suppliers. Even so, the researchers have been inclined to pay their attention much more to the outsourcing of non-core activities in the companies which are under course to refocus their businesses, and less or deficient attention to the coordinating methods or mechanism to manage the interrelation among network participants. Specially, the "fragmentation of value chains" occurs not only in the area of manufacturing ("intra-product specialization"), but, at the age of wide-spread division of labor, extends to the specialization of service production. How can the specialization and integration of business processed be realized in the large, complex companies in either manufacturing or service industries? In other words, for business units providing tangible products or intangible resources (services) and function as a process components in the whole business systems, are they suitable to be organized in a mode of modular organization, and how is the concept of modularity applied and adjusted? We try to answer the questions with a qualitative research method.

\subsection{Research methodology}

This paper follows the paradigm of qualitative research based on a case study. The research evolved along the following line: specification of research question, case materials collection, analysis of case materials based on theories, collection of supplementary data, inductive analysis along with theory-building, and generating conclusions in iteration.

According to the rule of theoretical sampling, we select Haier, a Qingdao-based Chinese company, as the case for study, taking both the typicality of the case and the convenience of data collection into consideration. As to the typicality of the case, Haier has grown to be the third largest white appliance manufacturers in the world. since starting its "market-chain based process reengineering" at the end of 1998 in order to enhance its corporate strategy of "fast responding to personalized demand" in the international market. However, what is the essential of this organizational change? Why the reengineered organization could upgrade its competitive advantage? Some researchers have applied mechanically some popular concepts or theories to explain Haier's reform effects and concluded with diversified and even conflict opinions $\mathrm{Su}$, 2001; Ma, 2002). We try to analyze this typical case deeply from the perspective of modularity and explore the underlying principles and trajectory in the formation and operation of the reengineered organization and its mechanisms to 
make Haier a strong competitor. Moreover, with the intention to collect multi-resourced data (mostly first-hand, plus some second-hand), we select the case of Haier from the consideration of convenience. In fact, ever since 1999, when Haier reported its initial reform as an innovated managerial achievement, we have been tracking this case firm and conducted several field surveys and interviews for assuring the materials used in the research analysis are sufficient and reliable. And recognizing that single case study is difficult to ensure the research's external validity, we try to base our inference with accumulated theories in the field of organizational design and strategic management in the course of generalize the findings induced from the case materials.

\section{Case analyses}

3.1 Haier's "market-chain" reform: The decomposition of business processes and the formation of modular organization structure

As one of the earliest internationalized manufacture enterprises in China, Haier and its top managers brought out a reform program of "(internal) process reengineering, (external) structural networking, and global competition" to assure the enforcement of strategic innovation. While bringing in big suppliers (components providers) and clients (customer) as business partners and building network-typed strategic alliance worldwide, Haier was also carrying out "market-chain-based process reengineering" internally ${ }^{1}$. The measures of reengineering include the followings: First, separate the departments of sales, purchasing and accounting from their formerly affiliated divisions and consolidate them into three independent "promotion sectors"- sales and marketing, logistic, and cash flow-to implement concentrated selling, purchasing, and consolidated settlement over the whole company. Second, separate former dispersed supporting or managerial functions such as human resource management, technical quality management, information management, equipment management, law, security from each department, and combine them to form an independent "service companies". Third, link these specialized process-units together using "market-chain", and design specified standards in "SST" terms according to the work targets of two sides of the (internal market)

\footnotetext{
${ }^{1}$ Zhang Ruimin identified that, when he accepted the interview of Ke En, senior editor of Harvard Business Review, about "Ultimate Target of Leadership" in 2007, Haier's reengineering since 1998 was "process integration", "function consolidating" or "process consolidating" (Zhang, 2007; Ke, 2007). In this paper, we adopt its original term, and name it as "'market-chain' process reengineering" or, shortly, "“market-chain' reengineering" to distinguish with the popular "business process reengineering".
} 
transaction, i.e., reward (Suo Chou in Chinese), compensation (Suo Pei in Chinese), and overleap (Tiao Zha in Chinese).

Looking into the transformation course of Haier's "market-chain" reengineering in the previous nine years, we find that: centering on the movement of the above "strategic innovation" is the theme of building the corporate organizational structure composed of two process systems: the primary processes ("core processes" called in early stage) and supporting processes. In the new structure composed by these two systems, the fundamental task of primary process units is to "create markets" and respond to customer demands/orders, and earn profits as well as creating market value. At the same time, the supporting process units are required to transform to profit centers via providing services for primary process units and external customers, but one clear premise is that "the goals of primary processes are exactly the final goals of supporting processes". The basic criterion for evaluating the performance of supporting process units is whether or not they add to the primary process units' value.

3.2 The fundamental frame of Haier's modular integration: Taking "SST" as a distinctly identified rule for coordinating the relationship among loose-coupled modules

If the decomposition of business processes is similar to that of modular products, then the design of modular organization requires the settlement of integrating mechanisms. Although isomorphic assumption may be taken to deal with modular integration in organizational settings, we have to be more cautious due to the difference between technical artifacts and social constructs.

As to Hair's case, when the efforts to consolidating formerly disperse business activities were carried out, the primary processes which were used to be integrated within each division are reengineered through decomposition, and constructed process modules. Here we need to make more unambiguous analysis on how to integrate those decoupled process modules to form a smoothly operated business system capable of creating market value.

According to Baldwin and Clark's wide-spread "guide to modularity", "visible design rules" in product design include three factors" : (1) An architecture, which

\footnotetext{
${ }^{2}$ The regulation on the interactions among modules is called "interface standards", and together with "testing standards", we use the term "standards" generally. Actually, Haier's "SST" standard stated latter in the paper, is corresponding to the "interface standards". The "test standards" are those quality specifications stating what level of one's work should meet. Considering the general meaning of "standards", Baldwin and Clark's book published in 2000, Design Rules, identified that the third factor was "testing standards", and drop the word "standards" from "interface (standards)".
} 
specifies which modules will be part of the system and what their functions will be; (2) Interfaces that describe in detail how the modules will interact, including how they will fit together, connect, and communicate; (3) Standards for testing a module's conformity to the design rules (can module X function in the system?) and for measuring one module's performance relative to another (how good is module X versus module Y?) (Baldwin and Clark, 1997). However, the current modularity theories have little concern with the concrete contents of these factors and their effects on the practices to integrate modular process systems in organizational settings.

By combining Baldwin and Clark's "guide to modularity" inferred from modular products design and our case study on Haier's business process system under evolution, we find evidence that the "SST" mechanism could be a preliminary interface standards linking service-providing support process units/modules and market-creating primary process units/modules.

\subsubsection{Architecture}

Before reengineering (Fig. 1a), the product divisions in Haier were self-contained, each with their own functions of purchasing and delivery, product development and production, sales and marketing, human resource management, finance, etc. After "market-chain" reform, "product groups" act as primary process units, creating value for its own and the company by meeting their market demands. Due to the function consolidation, "product groups" contain only a few core functions, including a product development unit (staffed with model managers and their SBU teams), a marketing support unit (staffed with product managers who are sent to Haier's 42 trade companies in domestic markets), and several manufacturing divisions divided on the basis of products. Other functions such as purchasing and delivery, sales, account settlement, and human resource, etc. are split off and concentrated into "promotion sectors". As supporting process units, they operate as internal profit centers. They are required to create a platform to serve the primary process units (internal customers). And, if they could satisfy the latter's needs, they make profit that is equal to the values they have created. In this reengineered relation, the primary process units are no longer vertically integrated. Instead, they focus on key functions responsible for "order creation" and "order acquisition", as shown in Fig. 1b.

\subsubsection{Interfaces}

After having implemented "market-chain" reform, Haier cancels the budget system of funding the supporting process units, and emphasizes the reward system based on the value created through their services. So the relation between 

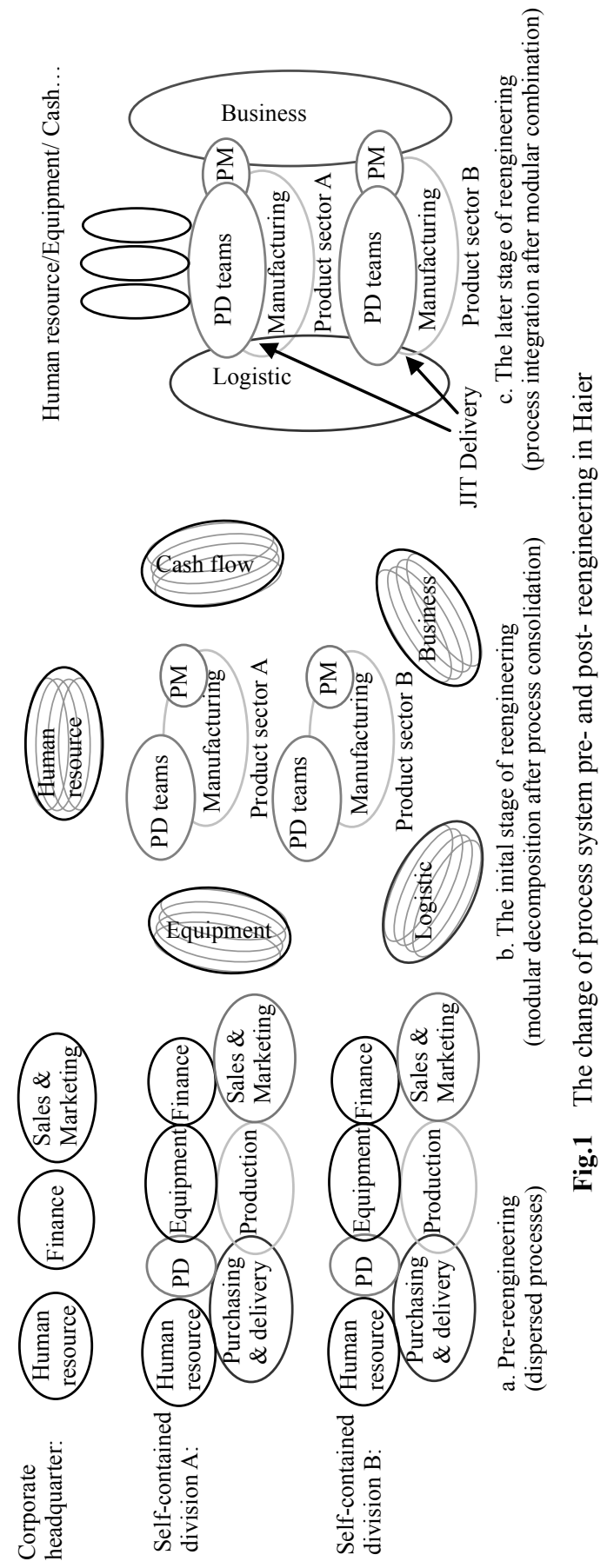
support process units and primary process units is transferred from former bureaucratic-styled one between service providers and receivers to the present "SST" mechanism implicating the relation of internal market trading. Here, the first "S", referring to reward (Suo Chou in Chinese), means that the service providers can charge the reward according to a pre-appointed rate from the demanders as internal customers if they reached a certain service level; the second "S", referring to compensation (Suo Pei in Chinese), means that the demanders, such as internal customers, can claim for the compensation at a pre-appointed rate if the service providers failed to reach the agreed-upon service level; and if no reward or compensation occurs in a business, the (computer) system will show no trade record, this is the "overleap (T)" referring to Tiao Zha in Chinese. This situation implies that it needs to sign a new contract, thus, create a new relation of internal (and possibly external) market transactions.

In Haier, not only support process units such as "order promotion sector" located on headquarter which is responsible for the sharing of innovative ideas and business practices are examined as the institution served to the realization of market targets of primary processes, but those profit centers such as "logistic promotion sector" and "business promotion sector" which ever treated as core process units in the early stage of reform, are identified latterly as supporting processes served to primary processes in the course of organizational institute updating. Similar to the metaphor which regards airports as a kind of "platforms" providing airplane take-off and landing services for airlines, Haier "business promotion sector" which is in charge of building sales network, is seen as a "platform" built for value-adding product sectors to sell products. Product sectors have to pay for their "shows" on this "platform", or pay for their utilizing this sales network. The "platform fees" are the reward (Suo Chou) earned by platform builders/operators. As Haier People (a newsletter) reviewed in an issue of early September, 2005, "logistic, domestic business, overseas business promotion...these support process units have charged much or less 'platform fees' when they provide services or build platforms for primary process units. When they devoted to run these platforms, they invested, so they were given no cause for any criticisms on the fees they charged. But supporting process units should not depend upon "platform fees" only, they need to create its market and create profits! To what extent do they help primary processes to improve their competitive competence? This is the profit sources of support processes!"

After "market-chain" reform, many Haier's businesses are completed in the process network meshed by market chain (SST). If we take the units intervened in a special process as the nodes, each node can be seen as the customer of its upstream nodes and the supplier of its downstream nodes according to SST mechanism, and there come into being a contract-linked relation between internal 
suppliers and buyers. As for why the suppliers (supporting process units) providing resources or services were functionally consolidated, the main consideration is that if those support process units serving multiple divisions or product groups (primary process units) are merged into one consolidated unit, then they can take the advantages of specific skills and economies of scale to improve the service quality and decrease the service cost. The aim of first two "measures of reengineering", which embodying the thought of modular decomposition of Haier's market-chain reform, is to form a platform infrastructure based on resource integration, for the sake of concentrating similar business. Regarding the effectiveness of the platform, it depends on SST mechanism coordinating the relation between resource/service demanders and suppliers.

\subsubsection{Standards}

After reengineering, Haier identified the standards of testing the performance of primary process unit as "whether or not having created the value for customers and to what extent the created value meets anticipated target". As for the standard of supporting process units, that is "whether (or not) have supported primary process, and if the support is sufficient." An accident occurring at assembly line of Haier Tumble Washing Machines manifests the effect of these standards in the operation of modularized processes in Haier. In October 2004, No.2 assemble line of Haimei division manufacturing tumble washer stopped production for one and half hour, and the reason was that one of the key components-control panels were not at right position on time. At that time, Haier washer division carried out "T-2" budget mode successfully, and assured all components were well prepared 2 days before production. Haier has already set the T-mode in group as a rule of solving the problem of material budget and delivery. However, the order referred in this production stop was required to deliver to customers at the third week of October, but the planner of order executive department found on $7^{\text {th }}$ of October that the total orders in the third week exceeded the production capability, so he decided to arrange the production of a proportion of the ordered products in advance. The production was ahead of the ordinary schedule, and No.2 line accepted this assignment, but the supply of components was not arranged according to the "T-2" mode, and the result was that the control panels needed had still not be manufactured when the deadline is due. After the accident, the budget competence of order planner was evaluated and punished.

Moreover, Since the order promotion sector that brought "T-2" mode into its platform did not keep attention on the implementation of the mode, was punished for not meeting its performance testing standard as stated that "the target of the 
promotion sectors is to constitute a resource platform after one problem, and then improve continuously, so as to solve all similar problems". By setting such standard as "not pushing the best practices to right locations, no innovation is reached", or more generally, "the value of supporting processes incarnates completely in the promotion and development of its flesh-and-blood related primary processes", Haier tries to get a type of similar problems rather than a concrete problem solved with the support of promotion sectors as support process units. In this way, the stated performance standards enhance the cooperation between the different process modules.

Apparently, Haier's "market-chain" reform breaks down the old form of organization system, and is inclined to build a new form of organization consisting of primary processes aimed at "creating market" and "respond to customer order quickly", and supporting process aimed at "creating value for primary processes". In the reengineered course, building resource platform and coordinating the relation between resource suppliers and demanders by SST mechanism become the basic manner interacted among process modules. Creating value for the customer in market and creating value for supported primary processes become the evaluation standards measuring the contribution of modular units of primary processes and support processes. Therefore, the "market-chain" reform in Haier brings out a new organizational stage.

3.3 The evolution of "three factors of design rules" of Haier's modular organization

In essence, the SST meshing principle proposed by Haier is a mechanism to coordinate the relation between loose-coupled business units by adding price-based motivation to the traditional mechanism of output standardization (Mintzberg, 1979), which introduce market mechanism into the operation of hierarchical structure. At the ever beginning of the reform, Haier adopted "circles" in its flowchart to substitute the "rectangles" in traditional organization chart, and pushed all business units to negotiate their "SST contracts" in pairs "among support processes, among primary processes, and between support processes and primary processes" to form an energetic and customer-satisfying "perpetual motion machine". If assimilating the process modules represented by "circles" to gear wheels, two solutions are available when the "mesh" is in failure, one is recomposing the standards of the gears and rectifying them; another is changing the gears. The former is only involved in the change of output and interface standards of relevant process units which are left untouched but neither themselves is preserved; and in the latter the "gear", i.e., the process units themselves are altered. Considering from these two sides, we need to analyze the 
composition of the modules and the mesh relation among modules simultaneously when we examine Haier's emergent modular organization structure. By reviewing the "three factors of rules" in modular design, we detect three changes in the course of Haier's "market-chain" based process reengineering.

\subsubsection{The evolution of organizational architecture}

Before "market-chain" reform, Haier had a self-contained division structure which integrated nearly all the needed functions. After process reengineering, divisions only take charge of the manufacturing of products and product sectors which are located a level up in divisions take the responsibility of product development and marketing (represented mainly by product managers); but other functions such as purchasing, sales and most functions of marketing, human resource and finance are concentrated and conducted by promotion sectors and other internal profit centers which, as far as the hierarchy is concerned, are parallel to product sectors. At the early stage of Haier's reform, product development was separated from each product sectors, while manufacturing, material and product flow (termed logistic and business promotion sector respectively) are treated as the firm's "core" processes. Zhu et al. (2006) comments, "represented no consistent relationship between Haier's technical innovation and marketing innovation... In long run, it might make corporate strategy deflect to sales and marketing, and ignore the exploitation and development of corporate core competence." Obviously, the remark was only based on the observation of Haier's "R\&D is a support process, but marketing (business flow) is a primary process". But the situation is under continuous and, maybe, unnoticed change.

As shown in Fig.1c, Haier has evolved to reorganize the functions of marketing support (carried out by product managers (PM) as SBUs individually) and product development (PD) (carried out by model managers who lead SBU teams) as primary processes, i.e., order acquisition and order creation, and regard them even more important than the manufacturing (order fulfillment) function in the value adding chains. They are all regarded as SBUs under the supervision of product sectors. At the same time, the roles of those units reporting to the logistic promotion and business promotion sectors are altered to operate as support processes, working in the similar patterns of human resource center, equipment maintaining, quality assuring and customer service sectors to help primary processes create value by providing platform resource and, in turn, received rewards from their (mostly, internal) customers. In general, the evolution of basic framework of Haier process system can be divided into the three stages in Fig. 1 
As Peter Drucker (1974) pointed out, firms need to place their most key functions in the centre of their organizations. The literature on "value chain" show that those activities having a strategic impact on value adding should be regarded as primary processes. But the judgment for strategic impact depends on different circumstances. In the book, Improving Performance, Rummler and Brache (1995) suggested from the perspective of contingency theory that the status of primary process depends on whether it could bring the firm with the competitive advantage. The dynamic evolution of the basic framework of process system in Haier is related significantly with the change of strategic status of the various functions. For instance, Haier recognized gradually that the SBU teams led by model managers were responsible for the new product development in each product sector. It is also responsible for "order creation", and product managers located within each product sector but work at 42 trade companies in charge with order acquisition. Both agents accept the strong market-driven incentives that reward them on the basis of "market performance" completely. Because product managers provide market information and participate in concept development and innovation planning in the early stage of product development and prepare to promote and sell these products after manufacturing, Haier places the marketing staffs within each product sector, in order to tighten the relation between these two primary processes, i.e., order creation and order acquisition. That is the reason for the separation of marketing activities supporting new product development from the ordinary marketing/promotion activities and sales in the business and overseas business promotion sectors identified as support process units in the later course of Haier's reform. As a fact, the change of the "gears" makes Haier win its competitive advantage by continuous product innovation and update in the global markets of white and black home appliance.

\subsubsection{The clarification and refinement of interface standards}

Zhu (2006) found that "the implementation of internal market mechanism in Haier resulted in a kind of market exchange relation between $R \& D$ and marketing, then absolutely induced the profit orientation between $R \& D$ and marketing, and formed the short-term target orientation inside two functional units." Actually, the latest flowchart of market-chain system ${ }^{3}$ in Haier shows that, without doubt, the relation between "order creation" (product development) and "order fulfillment" (production), and between "order fulfillment" and "purchase order" (components purchasing) are kept by the internal market contracts, but the relation between "order acquisition" (marketing) and "order creation" is an

\footnotetext{
${ }^{3}$ The chart in detail is "Haier market value synchronizing model" on its homepage (http://www.haier.com/cn/haier/culture/faith10_07.asp).
} 
exception-their "overlap" shown in new flowchart of Haier's reflects that they are not separated but composing one "big process circle" together. Furthermore, Haier not only places R\&D department and market support department under Product Sectors formally, but institutionally calls back all product managers scattered in 42 trade companies countrywide in monthly routine meetings hold by business promotion sectors. As soon as they come back, "the first thing that they do usually" is to find each model manager of the product types related to their assignments and feedback the information related to the future market trends and the problems in current products design and let R\&D personnel know better about the markets and enhance their products continuously. In this way, Haier is able to tie the product development and marketing together despite of the separation in formal institutional arrangement. As the dispatchment of product managers to 42 trade companies, which is supervised by "dual bosses" in both product sector and business promotion sector, Haier urges product managers to contact with model managers proactively in a variety of linkages.

In contrast with the western-styled of BPR (business process reengineering), there is generally "a process principal" who holds a high level position in the firm, managing the "white space" on the organization chart and play the role of auditors in the interface of several units. For this, Rummler and Brache (1995) said affirmatively, without a process principal, the problem of "white space" might be ignored. However, different from the researchers' proposition of having a part-time "process principal" assigned to a top manager, Haier resolves the coordinating problem in interface management by the mechanism of "personnel dispatching" between different sectors. As mentioned above, for fully utilizing resource of sales platform built by business promotion sectors, product sectors in Haier dispatch product managers located in their marketing support departments to work in the 42 trade companies affiliated to business promotion sector. Besides, for coordinating the interface between product and components purchasing, the logistic promotion sector dispatches their JIT delivery managers to product divisions in each product sector for assuring components delivered to assembly lines be in right position at a right time.

Similarly, those important managerial and supporting process units such as corporate finance, quality management, human resource, and equipment department also dispatch their personnel to the primary process units (statistics indicates that Haier human resources center dispatches more than 120 human resources directors in total). In addition to the dispatch, the frequent "job rotation" among managerial positions makes an institutional support for the connection between different process units. Haier not only depends on SST interface standard negotiated by internal demanders and providers, but recurs to various kinds of horizontal coordinating mechanisms, and makes "white space" turning into "jointly managed space" (as showed by the "overlapped" circles in 
Fig.1c). This may be interpreted that, among process modules decomposed in the course of "market-chain" reform, neither the interface configuration be a type of weakly-connected (loosely-coupled) under the mechanism of pure market exchange, nor the integrated type resulted from BPR in western companies, since in the latter situation, "process principals" take charge of all related activities in the end-to-end processes, and make the inspected and supervised processes coupled so tightly as to be considered "integrated". In contrast, in the 9 year track of "market-chain" reform, though mixed with the so-called "business process reengineering" (its real meaning may be better expressed by "business process consolidation", which is a new term used by Zhang (2007) recently), Haier has reached a phase transiting from internal market-type relation to semi-tightly coupled relation.

Although scholars frequently take the internal market mechanism within firms as a hybrid mode, or a mixture of market and hierarchical mechanism, but Haier's operation after "market-chain" reform shows that, rather than being an intermediate state of hierarchical-style authority mixed into market exchange, it tends to be that more and more hierarchical authority is substituted by the horizontal coordinating power of independent agents as internal service providers and demanders. Even though one could still term it a mixture system for the present organizational configuration in Haier, we should fully recognize the facet of radical change in the nature of "mixture" system.

3.3.3 The refinement of standards for evaluating performance of process modules

In the design of product modularity, the standards of performance evaluation are defined as "performance testing" of the product components (modules). By the clearly-defined testing standards, system integrators may conduct comparative functional testing for each single module needed to be integrated into the whole system and can therefore choose the best module from substitutable alternatives. However, how to judge whether an alternative module is the "best" one? In principle, we need to test its performance in terms of its contribution to the whole system.

Baldwin and Clark (2000) found that, in a system of modular design, performance testing could be conducted "at its own level" other than the level of system. But, "module-level testing requires greater depth of knowledge than system-level testing", that is "detailed knowledge about what the module contributes to the whole, as well as how different modules interact". With the standards for evaluating the performance assuring global optimization at the individual module level, we can encourage modular designers to conduct their test independently to acquire the value of "a portfolio of options" on the one 
hand, and on the other hand, ensure that unqualified modules not entering the system. Hereby, the performance evaluation standards are a necessarily part of "a complete set of design rules".

In general, for the systems consisting of highly compatible and substitutable modules, users can execute the task of system integration on their own, and thus the users' purchasing decisions reflect the optimization for choosing specific modules. Therefore, the market rule reflecting users' satisfaction level is valid for evaluating the functions (performance) of each module. But for the system whose modularity level is not as higher as the above "plug-in" system, it is very dangerous if performance evaluation is not conducted by taking the integrated modules as a whole, because if one module interacts with other modules unexpectedly, then the performance of the whole system would suffer. For incompletely modularized, "nearly-decomposed" systems, we must assure that the performance testing for one module is based on the global optimization instead of partial optimization.

Haier adopts the following three types of evaluation methods and standards for each consolidated process modules:

First, Haier includes the impact on the whole process system of an individual module into its negotiated standards of "reward" and "compensation" from the upstream/downstream process modules. For example, in a process to fulfill a 1-million-Yuan (RMB) export order, which is in charge of market manager, stock manager and business manager whose workload for the order is respectively 50\%, $30 \%$ and $20 \%$. When the market manager got this order from a customer and transferred it to the stock manager as an internal order, he should gain his revenue of 0.5 million Yuan according to his proportion (50\%) of workload. the stock manager got the order executed on time, and his revenue is 0.3 million Yuan according to his proportion (30\%). But due to a mistake made by the business manager, 0.15 -million-Yuan value of this order is unfulfilled. In this case, the customer ordered the 1-million-Yuan products actually received only 85 percent of the total, so business manager could get his 0.17 -million-Yuan revenue according to the former distribution policy, that is, 1 million $* 85$ percent $* 20 \%=$ 0.17 million. The accumulated revenue for all three managers is 0.97 million. This is the revenue distribution formula under the prior policy of "reward by working" before the "market-chain" reform. However, the customer's payment for her order is only 0.85 million (neglected the costs related to breaking the contract), but the company pays out 0.97 million, so a difference of 0.12 million occurs. Where is the difference from? After "market-chain" reform, Haier decreases the revenue distributed to the business manager from 0.17 million to 0.05 million. The logic "behind" this performance evaluation and reward is that, if the whole process only realizes the sales revenue of 0.85 million due to the business manager's mistake, then he should be punished, since his mistake turns 
the working of his upstream partners' work in a summed proportion of $80 \%$ "fruitless", so the business manager has to be "compensated" for the 0.12-million loss (i.e., 0.15 million $* 80 \%=0.12$ million), which is deducted from his 0.17 million revenue as a "reward". Thus, the net revenue of the business manager is 0.05 million. By the evaluation of "reward" plus "compensation", Haier overcomes the potential weakness of tunnel vision and egoism in the discomposed and market-driven process system. In the meanwhile, the spirit of concerning toward "(external and internal) customers" and "full-ranged processes" rather than that of "inward (his job)" and "upward (his boss)" concerning is installed incrementally in the course of reform.

Second, Haier introduces external competition (substitutability) into the way of modules' performance testing. The suppliers and buyers constituting the business exchanges are not only those units inside Haier; the introduction of "socialized trading" makes the relation between resource or service suppliers and demanders being substitutable. For example, technical facilities sector signed the contract of service for equipment management with product divisions based on their negotiation each other. If the service provider was not doing a good job, product divisions could claim compensation and also source outside equipment management service. As a result, the technical facilities sector had to provide superior services and a satisfactory price. In this way, what Haier did appears to be a change "within the organization", but actually forms "a big market chain connected to the market place" (Fischer, 1999).

By introducing substitutability based on the relation of market exchange, each process module as the service provider (resource platform) can conduct the test itself, and is not afraid if the created value might be underestimated by internal users, or if the reward (price) is fair for utilizing its new service. At the same time, the demander (user) may gain the advantage of "portfolio of options" at a better level, as Baldwin and Clark (2000) said, because the feature of internal service can be compared with the value of substitutable external service.

Actually, Haier has made lots of endogenous innovations and functional improvements independently after each process units became independent modules in "market-chain" reform. For example, the internal layer of electric water heater is made from steel board. In 2004, Haier tried its utmost to improve the cost-based competence of this product. The steel purchasing center in the logistic promotion sector, which operated in the way of "mini company", contacted actively with a number of steel manufacturers and got a piece of useful message from an international steel company which informing that, if taking the current machining process of the steel board changed in a slightly different way, then the cost of electric water heater may be decreased by $8 \%$ while ensuring the quality of the steel board used by the product. As soon as the cost manager and quality manager in electric-heating product sector captured this advice from 
purchasing manager, they organized experts to discuss and prove the feasibility, and then adopted the improved machining process in the second year.

For those business units which provide services to both internal and external users, the dual transactions may show some conflicts. How to handle conflicts between external and internal services? When being asked "where is your profit from, the price difference or the platform fee?" the purchasing manager in above example who pushed the process improvement of steel board used in electric water heater replied, "The profit of support processes is not simply calculated in terms of platform fees. We regard our profit related to the competence of primary processes, that is, to which extent the price we paid for our sourcing steel is lower than the market average price, and then we can help primary process units to improve their competence. This is the profit of our support processes!" This orientation to "help primary processes" makes the decoupled process modules, which are allowed to provide services to external users as well as internal counterparts, able to handle the interface problem openly and roundly, thus making the integration of process system different from pure market mechanism. It is this "openness" which forces Haier's reengineered process system capable to keep enough flexibility to absorb the emerging innovations and experiments in independently-operated process modules.

Third, Haier employees "combinatorial system-level tests" designed for performance evaluation of primary process units. For model managers and product managers who function as SBUs respectively in the "order creating" and "order acquisition" processes, Haier evaluates their performance against the market value realization of the products developed and promoted by them. In this way, they become SBUs with their reward or punishment linking tightly with their effectiveness. A model manager responsible for the development of tumble washing machine said, "Formerly the wage was always paid by product sectors before the market effect could be seen, now it is no longer; 'no milk' if we hasn't realized the should-be effects or delay the realization of the effects." Matching with this "completely results-orientated" incentive system, Haier installed the SBUs' profit-and-loss responsibility to such lower level agencies as model managers who are supposed to take in charge of the whole process of product development from the market survey to update of a specific type of product and, accordingly, paid solely for the results. For example, a model manager of air-conditioners needs to take responsibility for the all the tasks including market information collecting, product planning, industrial designing, the design of product structure, refrigeration cycling system and electric control, validating, product certification, testing, trial manufacturing, public offering, new product tracking, quality improving, and others. For this "from end to end" responsibility, model managers learn to gain the insight and capability of managing a new product from idea development to public offering, showing, and profit making, 
then further to market exiting and derivative product developing in a pattern of "product life cycle management". This is the way of evaluating the performance of model manager who takes the accountability to combine multiple functions related to the development of a successful model (product) even though his position is located narrowly in the process module of "order creating".

As to the performance evaluation of the product managers in the process module of "order acquisition", Haier used to reward their efforts based mainly on the volume of sales, plus some secondary metrics including "promoting, warehousing, and passing rate of product representatives under their supervision", which encouraged product managers to win "the large orders". After 2005, Haier began to push SBUs' profit-and-loss statement for product managers in the firstly trial refrigerator and washing machine product sectors as well as Haimei division, in which "the sales revenue is subtracted by promotion expense, quality loss and secondary delivery." A product manager from Qingdao refrigerator product sector said, "The incomes of product managers were formerly from sales mainly, and the expenses were fixed every month. It is ok so long as the actual expenses were kept lower than the fixed level. The product managers could not get any benefits from any possible reduced input. At that time, product managers looked like to spend others' money. Now the incomes of product managers are from the added value, inducing them to calculate carefully all the trade-offs. The SBU profit-and-loss statement brings "quality loss" and "secondary delivery" into the consideration of product managers. Product managers begin to pay more attention to the proportion of marketing staff, and dismiss those unnecessary persons and recruit key persons in time. Moreover, for a product manager, the loss of "secondary delivery" means that he has to send the products to the end customers, rather than send the products to the stock places of the sales channels. It is not counted into market performance if the product is kept in the stock of a store department rather than "flowing" into the hand of end customers. With this revised responsibilities, product managers have to consider whether the products promoted match the demand of markets and thus are forced to communicate intently with other actors in the process modules of product development and manufacturing.

Above diversified ways of performance testing reflect that Haier admits the heterogeneity between process modules. In contrasted to the "BPR" mode of organizing toward integration rather than specialization, which is currently popular in Western, Haier's reform is in a sharp different direction. However, absorbing the spirit of emphasizing the "wholeness" and "customer satisfactions" of all reengineered processes, including primary and support processes, into the functionally specialization process consolidation in the course of decomposing the former integrated process system within product divisions, Haier endows the "market-chain" reform on the one hand and overcomes its shortage of local 
optimization on the other hand. The practice in Haier shows that, towards the direction of enhancing specialization rather than breaking down specialization as in "BPR" type of reform, the firm has the alternatives to fuse "integration" (i.e., modular integration rather than process integration) into "separation" and realize a modular organizational design with "(modular) integration" and "separation (decomposition)" combined properly.

3.4 The co-evolution of three design factors in the formation of Haier's modular organization

The practice of "market-chain" reform in Haier shows, while the whole business process system could be decomposed into various process modules performing different functions, the smooth operation of modular process system requires a semi-strong level of coupling with specific and integrative features. In Haier, the decomposition and integration of the evolving modular organization is a dialectic co-evolutionary course. During nine years of process consolidation and adjustment in Haier's "market-chain" reform, the decomposition points and the functional positioning of each process module are not the same all the way. Instead, Haier keeps on adapting its reengineered process system to make the interface connection more naturally (and cost economically) and the evaluation of each module's contribution to system performance more rationally (in the terms of global optimization).

Although the above inductive analysis on Haier's case is stated point by point according to "three factors of design rules", the building and evolution of new organizational structure is a systematic process. Haier's modularity trajectory is by no means the result of individual rationalization of each factor. Actually, the change of functional position from "core" (primary) to "support" processes for logistic and business promotion sectors represents not only the change of the architecture consisted of two types of processes, but the change of operation targets (the standards of performance evaluation) and cooperating patterns of their sub-modular processes, such as "purchase order", "order sales", and so on.

As for the integration of the overall organizational system, the coordination among "order acquisition", "order creation" and "order fulfillment", and the change of performance evaluation of model managers' responsibility for product development and their actual roles as interface managers responsible for satisfying customers "from end to end", as well as the performance evaluation for support processes based on the operation goals of each module or the global optimization of the whole business system, all of these reflect the incremental course of the rules in forming Haier's modular organization, which is the result from the interaction and mutual adaptation between the architecture, interfaces and testing standards. These three factors of modularity are co-evolved by 
interacting with each other simultaneously, and bring the overall rationality for the whole business system in Haier.

\section{Discussion}

Earlier case studies on Haier which were conducted from various perspectives have shown that, "Haier has got sustainable development by sustainable innovation" (Xiao et al., 2004), and "the reform of management in Haier is (one of) the important factors for keeping its fast growing" (Ouyang, 2003). While its importance as a "change and innovation of management and operation mechanism" that Haier pushed continuously in last nine years was well recognized, the question remains, that is, what is the essence of the organizational change embodied by the "'market-chain' process reengineering"? What is the effect on Haier's overseas competitive strategy? Whether the basic principle underlying Haier's reengineering course is generally meaningful to the explanation of modular organizational design and its operation? We focus the discussion mainly on these questions.

4.1 The driver and its function in the evolution of Haier's modular organization mode

Palepu et al. (2006) concluded that overseas competitive strategy of Haier's home appliance is "product diversification" and "fast response". For the need of fast responding to demand of localization or personalization in overseas markets, Zhang Ruimin has conceived to adjust the mode of organizational operation fundamentally when he proposed Haier's internationalization strategy in 1998.

Serving the need of its internationalization, Haier tries to form the alliance relation of "structural networking" with outside organizations such as big global suppliers and retailers, so as to improve its competence. Considering the weak brand influence at that time, Haier needed to conduct the "process reengineering" of its internal organization, for gaining its attractiveness and the bargaining power with potential global partners. What Mr. Zhang said about "the advantages of reengineering the processes" in a special interview with Ke En, the senior editor of Harvard Business Review, revealed Haier's original intention of "process reengineering" since 1998, "each division did purchase for itself (at that time), our purchasing power was dispersed and it made favorable price almost impossible." "And that when marketers from our refrigerator, air conditioner, and washing machine divisions all showed up separately at the same store to negotiate promotions, the store's management was being pestered beyond endurance-and we were doing nothing to convey a uniform corporate 
image."(Ke, 2007) After reengineering, the consolidation of similar processes over the whole company induced an internal networking relation for the long-run "market-chain" exchanges between product sectors and the logistic and business promotion sectors and the like. The concentrated purchasing, selling and settlement brings about the economies of scale in the consolidated functions and facilitates the company to build a more long-lasting network relation rather than arm-length exchanges with external organizations. According to our case survey, the final result of the "process reengineering" in Haier is that the business units having independent profits are "meshed" together by much stronger relation than that of market type, whatever inside or outside the company, forming a network structure cross the functional and organizational boundaries. In interpreting its nature of the "'market-chain' process reengineering", we conclude that a modular organization emerged from the consolidation of business processes in Haier.

In the literatures conducting research by the logic of "intra-product specialization", strategic flexibility is defined as the capability to connect the suppliers of components or middle products flexibly, and to form the complicated and diversified resource combination (Worren et al., 2002). When we extend our inquiry from the organization of product production process to cover the whole business system, we found, especially from the case of Haier, that the operation of corporate business not only needs the inputs of tangible products, but the support from intangible resources or services. The modular units of a business organization include not only the procedure, segments, and circles in the course of product manufacturing, but also the units of various services providing. Furthermore, external competition (substitution) can be introduced increasingly into the evaluation of modular performance, which helps enlarge the diversity of resource combination, and improve the strategic flexibility in business operation. Hereby, we reach the following views:

Proposition 1 The diversification afforded by modular units offering all kinds of tangible and intangible resources is instrumental to enhancing the strategic flexibility of the whole company.

\section{2 "Separation" and "integration" in the building of modular organization}

Since Haier has implemented "market-chain" reform, domestic researchers could not reach an agreement on the form and basic features of Haier's reengineered business system. Su (2001) found, "Haier re-designs its former functional structure and divisions, and transfers former functional structure into streamline network structure", and the network structure is the result of "business process reengineering". This statement misunderstand the meaning of "process reengineering and integration" using specifically in Haier when former dispersed processes (which means "functions" actually) were "integrated" for 
"consolidating internal resources". It could be seen that the consolidation of functions or internal resources embodies mainly the feature of "decomposition", i.e., process separation which is in sharp contrast to process integration as usually referred to in "BPR" literatures (Hammer and Champy, 1993; Wang, 1997; Wu et al., 1998).

So far as the "market-chain" process reengineering" in Haier is featured by the integration of the resource scattered formerly in every division to realize "functional consolidation" inside the company, a very clear fact is that the reform results in the enhancement of specialization or modular decomposition rather than the integration of its business processes. So the sequencing question is how to realize "modular integration" after the enhanced specialization? Different from process-based organization built on the standpoint of process integration of breaking down specialization which is a popular mode in western companies carrying out the revolutionary reform of "BPR", for Haier's reengineering effort centered around the integration/consolidation of internal resources separating a variety of support processes from product sectors (primary processes), a key task determining the operation of this modular type of organization is how to coordinate the functions of specialized units (process modules) and realize the process integration afterwards (Mintzberg, 1979), rather than the built-in process integration featured in "BPR" (Hammer and Champy, 1993). Comparing to the latter's streamline process systems, Haier is more like a functional structure with each process unit performing a specific kind of activities, resulting in the decomposition of the whole business processes into modules, and let their interfaces of related modules governing by "market-chain" relation.

Relying on our in-depth case investigation which combined our more than three rounds of field interviews with a variety of second-hand materials, we try to analyze the relation among the decomposed process modules in Haier beyond the ordinary logic of "marketism" which would only describe the surface feature as Haier started its reform in the criticism of hierarchy and pushed internal market exchanges and payment basing solely on results. Different from the market mechanism which keeps an extremely weak, loosely-coupled state of relation among business units and turns them into "isolated islands in the sea of market", Haier has been evolving to solve the shortage of internal-price-linked system after its "market-chain" reform, and tries to establish the system-level testing of performance of independent business units as well as pushing them involved in both the internal and external market exchanges, thus making the various process modules more readily integrated for the sake of the smooth of the whole company as a "perpetual motion machine".

From the perspective of modular decomposition and integration, we come to a conclusion: after functional consolidating and process separation, Haier keeps to explore positively the realization of modular integration of independent business 
units with their functional positioning in a limited number of stages in either the primary or supporting processes, then forms a semi-strongly coupled network structure which can create and combine the needed internal and external resource flexibly. Furthermore, many business units with operational independence take part in "networking" practices inside and outside Haier and make the separated process modules not isolated from each other, but rather, being more like the gears with different functions meshing together to transfer the energies and work media from each other by well-meshed cogs, and then make the whole organization operating well and with a high speed. It is shown in our case study that the decomposition of business processes is only one side of the modular organizational design; the other side is that the independent process modules should be integrated into a modular business system through various ways of combination and coordination. Those modules which can not be integrated organically are useless unless they could, as fractal cellular, produce all the functions needed by a system. In a word, modules are only components of a system. Different from the traditional, self-contained division structures in which all functions needed are integrated inside the individual division, the business system of Haier after its modular decomposition should be consequently meshed together through a set of modular integration mechanisms. Based on the requirements of integration following after decomposition, we can conclude the following point of view:

Proposition 2 Modular decomposition and modular integration are two sides linking tightly; their coordination and synchronization determines a firm's (or any other complex system's) overall performance.

\subsection{The condition and course of the formation of modular organization}

The firm is a complex economic organization, and its course of modularity is influenced by many factors. Now a popular view in this field is, the evolution of modularity complies with the path of "technical modularity-product modularity - industrial modularity (modular clusters) - organizational modularity (Baldwin and Clark, 2000; Hao et al., 2007). Basing on the traditional views about product modularity but emphasizing the transformation of value adding chain is "the combined result of market coordination, organization coordination and technical coordination, $\mathrm{Xu}$ and $\mathrm{Li}$ (2005) proposed a modified evolution path "from technical modularity to market modularity, and then to organization modularity". Basing on the analysis of organizational feature of the firms having adopted the "internal market" coordination mechanism to govern the inter-organizational relations in industrial modular clusters, the authors suggested that, comparing to the production of integrated products, the firm that produces modular products "is prone to choose external suppliers" and, in 
making the choice, "generally does not choose its former suppliers"; further more, during the reconfiguration of supply base, the increase of "market width" (the number of potential suppliers) provides the focal firm with greater chance to choose new external suppliers to provide components for the production of modular products.

Worthwhile to notice, the above points are based on theoretical deductions. Comparatively, an empirical research on laptop industry in Japan and USA (Hoetker, 2006) has shown that, product modularity does not necessary push the focal firms to outsource from external suppliers; while the relation between product modular and the substitution of external suppliers is very strong. The conclusion of this empirical research is that the higher level of product modularity will make more frequent and "more freely" for the firms to reconfigure its supply chain. But it is not proven if there is a strong correlation between product modularity and "outsourcing".

As a whole, the research on modularity has not arrived at a clear and consistent conclusion regarding the relation between product modularity and organizational modularity. Our study based on the case of Haier shows that, if we extend the observation from product manufacturing processes to the whole processes of business operation, we can predict or explain the formation of modular organization from the perspective of the diversified and independent service providers as modules or components of a modular system. The definition of modular organization under the logic of "intra-product specialization" are under the view that the units involved in the process of product design and manufacturing are loosely coupled; similarly, our definition of modular organization after the expansion of the observation frame refers to the loosely-coupled organization status formed by the flexible combination of independent business units. Hereby, as the components of a modular organization, the independent business units, taking Haier as the example, includes not only the primary process units responsible for order acquisition and order creation, but the units in the support processes which are responsible for providing services for primary processes. Furthermore, the manufacturing units of components and semi-finished products, and even the sub-assembly and final assembly units could be regarded as a kind of service providers. In this case, the production may become a support process gaining reward with their service exchange to assist the value creation in primary processes.

In Porter's "value chain" theory, the activities such as raw material supply, product manufacturing, product delivery, marketing and service, related directly to the process and circulation of the goods, are ranked as basic value-added activities of the firm. Influenced by this theory, Haier has taken its newly consolidated logistic and business promotion sectors as "core processes" at the beginning of its "market-chain" reform. During the reform, Haier came to realize 
that it was impossible for a firm to do good in every stage of value chain. As Zhang Ruimin presented his view about reform at Wharton Business School in April 2001, "value chain' is no longer suitable for enterprises in this information time". This view directly resulted in the building of Haier Logistic Company as a third party institute providing both internal and "social" logistic service, the logistic promotion sectors and later the business and oversea promotion sectors as well. These affiliations are all identified as the units of "support processes". As top managers in Haier enhanced their understandings in the relation between primary and support processes, the whole business process system in Haier evolves toward a network of independent business units connected by the mesh mechanism of "market-chain". Thus, we got the conclusion as followed:

Proposition 3 The understanding of the process system's decomposable features and the relationship between primary and supportive processes, accompanied by the economical independence of business units with market-oriented incentives, facilitates the formation of modular organization.

The above proposition shows that it is only a second-order problem whether or not external suppliers are included as modular components in the network structure of the firms (as Haier) in the course to (re-)build the modular organization. The first-order problem in the front of this is that whether the current business process system can be decomposed into independent units which operate independently. The introduction of internal market operation mechanism in Haier results in the decomposition and independence of the formerly integrated business processes. The managerial and support functions (such as human resource, equipment management) formerly being set up in the corporate headquarter and the process units (such as logistic and business promotion) that once was seen as the "core" value-added activities are transferred into support processes, thus become the modular units open to external demanders under the policy of permitting to provide "social" services. Correspondingly, primary process units in Haier can substitute the internal service providers by choosing a better partner upon the comparison of cost-benefits among available internal and external "competitors". This logic of modular decomposition of business process and the integration by substitutive combination explains the currently conflicting viewpoints: product modularity did not help firms move activities out of its boundary (Hoetker, 2006) vs. the firm producing modular products, comparing to the firm producing integrated products, is prone to choose external (new) suppliers (Xu et al., 2005).

It is shown in our case that the modularity of products or business processes is not a sufficient condition for the formation of modular organization. And we may conclude further that the product modularity is not a necessary condition for organizational modularity either. For the latter, taking the product manufacturing as a kind of service, we may see that if the contents of solution provided to 
customers are a bundle of services - usually termed as "extended product" — even though the physical product itself is integrated (non-modular) in nature or in its current architecture, then the firm can act as a system integrator combining plenty of services in an integrated solution. In this situation, if and only if (a) the services matched with physical product holds a big share in the total value created and (b) they can be divided into different items and possibly outsourced, that is modularized, then the system integrator can adopt the mode of modular organization, taking the manufacturing of physically integrated product as a module of the whole solution-production process. Putting extremely, even if the "front-end" service (solution as an intangible product) could not be divided into each independent modules, i.e., the primary process is non-modular, but the provision of the service is very complicated and requires for series of "back-end" assistance and support which may be decomposed, then the relation between principal process and supporting processes can be coordinated by the mode of modular organization under the condition of decomposable service processes. By this, we conclude the product modularity is not a necessary condition for organizational modularity. In this very meaning, we propose confidently that it is difficult to deduct whether or not the firm would adopt a modular organizational design to build a network relation with independent suppliers, from the only standpoint of product modularity which is not the necessary condition for the formation of modular organization.

From the sufficient condition of the formation of modular organization, we recognized that, although the product manufacturing and other business processes are decomposable, the firm can not become the modular organization if the units executing specific tasks of functionally separated processes are not independent at least economically. As researches found, after the components of a system are decomposed, each modular unit must have enough initiatives to do experiments in improving the functionality of the module which relates on its survival, thus bring the combined or integrated system with competitive advantages. In the extension to modular organizational design, each service suppliers should be motivated to form or improve its own distinct technical capability. Hence, economically independent operation of service providers with or without legal independence (the former refers to the internal business units whereas the latter to external ones) and the readiness to be combined together or reconfigured are two of sufficient conditions for the formation of modular organization.

Let us begin with the condition of "independent operation". Economic organization is different from product systems in which modules can be built naturally after decomposing the constitutional components technically. In the case of Haier, with the decomposition of former business process in "market-chain" reform, the independent interest and innovative behaviors of each 
business unit are respected and encouraged during the sequential market-oriented "SBUs" operation system. Without the correspondent market-driven performance evaluation and motivation, pure "technical" reengineering of business process architecture can not finally induce the modularity of the business organization. Certainly, the legal independence is not the necessarily pre-condition of economic independence. Haier's action of "all employees as SBUs" has shown that, economic independence can be implemented inside corporate legal boundary. Taking extremely the independence in only "legal" way as the required condition for modular organization will produce conceptual bias toward internal business units as components (modules) of modular organization, and unavoidably leading to the exclusion of internal business units in the networking of value nets and, thus, ignore the actual realization of modular organization design inside firms (reference to the reviews of Lei et al., 2004). Actually, if the firm as a system integrator is inclined to choose the best modular components (service providers) among the inside and outside candidates, then the consideration of transaction cost is also an important factor besides the comparison of technical capability of each module. If the experimentation or innovation at the modular level is conducted and scattered among legally independent firms, and if the coordination expense for its "option of combination" is bigger than that of modular combination among economically independent units inside the firm, then the internal providers will be preferred, taking the difference of technical capabilities between internal and external providers are small enough. Of course, the small difference in technical capabilities as the precondition of the choice requires the status of economically independence of the internal providers which would get the incentives for the continuous experimentation and innovation on their processed modules on the one hand, and gain freedom or "invisible private information" of improving their modular designs on the other hand.

The current researches on modular organization mainly focus on inter-organizational network among firms, and focus mainly on analyzing the relation between product integrators and component suppliers, with obvious ignorance of internal service providers (semi-independent business units inside the focal firm). Some researchers concluded in hasty such a wrong judgment as that "it is not modular organization if the firm did not transfer its activities to outside suppliers". The case analysis in this paper shows that, even if all of the modular suppliers are inside the firm, they could act as nodes of networks to constitute a modular business system. It is just a second-order problem whether modular suppliers are inside or outside firms. A much more important and first-order problem than that is: whether the whole business system can be divided into a variety of business units - internal modular suppliers, which is economically independent, and can conduct modular experimentation and 
innovation by its own. Under the condition of equal technical capability, inside and outside modular suppliers are substitutable modular units for each other, and their existence simultaneously makes the network inside and outside the firm being intervened together and then become an integrated value web.

Then we analyze the condition of "readiness to be combined". Whether or not the modular organization will acquire the advantage of "option of combination" among loosely-coupled modular units depends not only on the predefined visible rule of interface relation, but on the easiness of sequential modular combination or integration, which is to what extent decided by each module's operating targets aiming at partial optimization or global optimization. For potential "symptom of improper" of selfish departmentalism and marketism pursuing short-term interest, Haier pushes out "SBU (strategic business unit)" mechanism cultivating long-run and overall view for all employees and, in each Product Sector, sets up a specific department responsible for "unifying the shared value of market chain". The purpose is to install the idea of process integration into independent business units for them to take the responsibility for satisfying the end customers and the corporation ("outside-" and "overall-" oriented) by embodying the "market targets" as evaluation standards of each modular unit. In the course of improving by practicing, Haier adjusts the architecture constituted by the modular primary and support process units, clears up the interfaces for correlated modules, and establishes the diversified performance standards for evaluating different modular units. All of the above practices show that economic systems with complex adaptive characteristics can evolve into a modular mode of organization, of which the connection among internal modular units is reached firstly and then expands to a more open scope of connection outside the firm. From this analysis, we can conclude the following:

Proposition 4 The more the number and diversity of decomposed business units in a modular organization, the more complex the way in which the business system operates; consequently, the stronger the evolutionary feature in the course of modular integration.

\section{Conclusions}

The current understanding for modular organization is at the stage of defining abstract concepts. By analyzing the Haier case, this paper illustrates the concrete meaning of modular organization with a detailed and clear description. As Siggeikow (2006) found, the value of case study could never be undervalued even using it as a pure illustrative tool, especially when the meaning of the concept was unclear. We choose the case of Haier by "theoretical sampling", and use the case to clarify our understanding with the feature, construct, and 
operational principle of modular organization. This is one of the basic contributions of this paper.

The case study in this paper is not only illustrative but explanatory to some extent. By the analysis of modular decomposition and integration of Haier's business processes after "market-chain" reform, the paper explores the principles of structural design of complex systems which are nearly-decomposed and its mechanisms to influence business performance. The research shows, we could increase the strategic flexibility of the whole system with diversified modular constitution in terms that both service providers and product manufacturers are taken together as modules of the business organization. Meanwhile, as the components of the system increase in number and variety, the complexity of the system are also increased. As two sides of contradiction, the modular decomposition and modular integration need to be unified organically for assuring the effectiveness of the whole system. The practice in Haier shows, the modularity itself of product or business process is not the sufficient condition of the formation of modular organization, so much as the product modularity is not the necessary condition of organizational modularity. As gear wheels of a "perpetual motion machine", only if process modules of business system are integrated in the way satisfying the condition of "independent operation, and readiness to be combined", then the whole process system will be transformed into a flexibly-linked and well-operated one.

Comparing to the thought of "BPR" (business process reengineering) advocated by Hammer and Champy (1993), which replaces segmented functions with integrated processes in prior, the modular integration or combination among separated functions, as showed in Haier case, is realized afterwards the preliminary design of modular decomposition embodying specialization rather than integration. Further, the decomposition and integration of process modules are subject to adjustment in an evolved course to increasingly improve the rules of modular design. And the understanding for the correlation of different dimensions of design rules in a complex system is not perfect. Considering this feature of evolutionary course, i.e., the dynamic process to form a modular organization, we term Haier's new mode of organizing as modularized organization rather than modular organization which usually refers to the one designed well in once.

Although the case in this paper is selected from home appliance industry in which products are generally characterized by modular design, we identified that product modularity is not sufficient for organizational modularity, showing that organizational modularity is correlated much more with decomposable feature of business processes than with that of products which are readily modularized. By definition, a module is the collective unit lower than the overall system. As long as the coupling among components in this unit is tight, while the coupling with 
components in other units is relatively weak (loosely-coupled), the character of this correlation gives the system with the nearly-decomposed feature of modular structure. As for whether or not the module itself could be divided into smaller units, for example, whether product manufacturing as one part of the whole business system could be divided into smaller process modules such as the supply of parts or materials, the assembly of sub-systems and final products, delivery to markets and the like, is only the affair inside "hidden modules" (which is called by Baldwin and Clark (2000) as "the subsplitting of modules"), and is not always displayed in the course of decomposition of the overall system. In other words, its impact is not directly for process decomposition at the level of system whether a "hidden module", such as product manufacturing, can be divided.

The analysis of Haier's case in the paper has adopted a standpoint to concern the decomposition and integration of business process system (rather than the decomposition and integration of product system in current literature) to make a qualitative research on the principles and features of the formation and operation of modularized organization. This theoretical perspective establishes the base for the generalization of conclusions. The propositions we concluded from analytical induction of Haier case is not only adaptive for other manufacturing companies in which their products are decomposable (herein, the modularity of manufacturing process is at the system level), but also for those manufacturing companies in which their products are integrated and, thus, their modularity of manufacturing process could not be subsplitted (herein, the subsystem level is concerned). Further more, for those service enterprises or institutes whose products are intangible outputs (i.e., services) that process of production as a module or subsystem may or may not be decomposable, so long as its business system as a whole is quite complicated and prone to decomposable, then it is suitable for the formation of modular organization ${ }^{4}$. Whatever is the companies in manufacturing industries or service industries, under the strategic orientation to promote specialization of functions and further to the decentralization of managerial authorities, the mode of organizational modularity which embodies the thought of "integration" following "decomposition" is an option fitting for viable operation of complex business systems.

Acknowledgements This research is supported by the National Natural Science

${ }^{4} \mathrm{Lu}$ (2007) listed some cases for manufacturers and service providers which could outsource their commercial services such as IT support, human resource, finance and accounting, salary payment, call center, etc. when he conducted the research on international outsourcing. It could be concluded that these processes could be divided or decomposed. As for whether these process modules of services were outsourced from firms in other nations, it was decided by the level of difficulties in achieving international modular integration or coordination. 
Foundation of China (No. 70571082), and the "985" project of Renmin University of China. Thanks to Haier's support for case survey and interviews, as well as to Associate Prof. Wenpin Tsai of Smeal Business School, Pennsylvania State University, USA, for his advice on implementing case-based qualitative research.

\section{References}

Aoki M, Ando K (2003). An Age of Modularity: The Nature of New Industrial Structure. Shanghai Far East Publishers of China

Baldwin C Y, Clark K B (1997). Managing in an age of modularity. Harvard Business Review, 75(5): 84-93

Baldwin C Y, Clark K B (2000). Design Rules: The Power of Modularity. Cambridge, MA: MIT Press

Brusoni S, Prencipe A (2001). Unpacking the black of modularity: Technologies, products and organizations. Industrial and Corporate Change, 10(1): 179-205

Brusoni S, Prencipe A (2006). Making design rules: A multi-domain perspective. Organization Science, 17(2): 179-189

Chen J, Gui B and Chen Y (2006). Case investigation of complex product systems innovation based on modularity development. Science Research Management, 27(6): 1-8

Daft R L, Lewin A Y (1993). Where are the theories of the 'new' organizational forms: an editorial essay. Organization Science, 4(4): i -vi

Drucker P F (1974). Management: Tasks, responsibilities, practices. New York: Harper \& Row

Eisenhardt K M, Graebner M E (2007). Theory building from cases: Opportunities and challenges. Academy of Management Journal, 50(1): 25-32

Fischer W A (1999). Building Market Chains at Haier. CEIBS GM939/2000 EFMD GM939; in Building market Chains at Hair-IMD Cases (ed. by Haier University, 2006, 6)

Garud R, Kumaraswamy A, Langlois R N (2003). Managing in the Modular Age: Architectures, Networks, and Organization, Malden, MA: Blackwell Publishers Ltd

Hammer M, Champy J (1993). Reengineering the Corporation: A Manifesto for Business Revolution. New York: Harper Business

Hao Bin, Ren Hao, Guerin A M (2007). Design of organizational modularity: Basic principles and theoretical structure. China Industrial Economy, (6): 80-87 (in Chinese)

Hoetker G (2006). Do modular products lead to modular organizations? Strategic Management Journal, 27: 501-518

Ji Xuehong, Chen Rongqiu, Tang Zhongjun (2004). Research on modularity and integration in PC industry. China Industrial Economy, (10): 91-96 (in Chinese)

Ke En (2007). The final goals of leadership: A special interview with Haier's CEO Zhang Ruiming. Harvard Business Review China, (1): 70-79

Langlois R N (2002). Modularity in technology and organization. Journal of Economic Behavior and Organization, 49(1): 19-37

Langlois R N, Foss N J (1997). Capabilities and governance: The rebirth of production in the theory of economic organization. Danish Research Unit for Industrial Dynamics, Working Paper No. 97-2

Lei Ruqiao, Chen Jixiang, Liu Qin (2004). Comparison of organization model and their efficiencies based on modularity. China Industrial Economy, (10): 83-92 (in Chinese)

Lu Feng (2007). Study on china's participation of international service outsourcing. Economy Research, (9): 49-51 (in Chinese) 
Ma Gang (2002). Haier's pattern of operation process restructuring and its economic analysis. Policy-Making Reference, 15(1): 7-11 (in Chinese)

Mintzberg H (1979). The Structuring of Organizations, Englewood Cliffs. NJ: Prentice-Hall Inc

Ouyang Taohua (2003). Competing based on high level for China's companies: Case study on Haier. Management World, (2): 116-126 (in Chinese)

Palepu K S, Khanna T, Vagras I (2006). Haier: Taking a Chinese Company Global. Harvard Business School Cases 9-706-401, Boston: Harvard Business School Publishing

Rummler G, Brache A (1990). Improving Performance: How to Manage the White Space on the Organization. Char San Francisco: Jossey-Bass

Sanches R, Mahoney J T (1996). Modularity, flexibility, and knowledge management in product and organization design. Strategic Management Journal, 17: 63-76

Schilling M A, Steensma H K (2001). The use of modular Organizational Forms: An industry-level analysis. Academy of Management Journal, 44(6): 1149-1168

Siggelkow N (2007). Persuasion with case studies. Academy of Management Journal, 50(1): 20-24

Simon H A (1962). The architecture of complexity. Proceedings of the American Philosophical Society, 106: 467-482

$\mathrm{Su}$ Huiwen (2001). Haier's managerial innovation: Market chain and business process re-engineering. Nankai Management Review, (1): 42-48 (in Chinese)

Wang Fengbin (1997). Leaders and Modern Firms' Organization. Economics and Management Publishing House (in Chinese)

Worren N, Moore K, Cardona P (2002). Modularity, strategic flexibility and firm performance: A study of the home appliance industry. Strategic Management Journal, 23(12): 1123-1140

Wu Peiliang, Zheng Mingshen, Wang Fengbin (1998). The Theory and Designing of Structure. Economics and Management Publishing House (in Chinese)

Xiao Hailin, Peng Xinglu, Wang Fanghua (2004). A born mechanism model for a firm's sustained growth: Based the case study on Haier. Management Word, (8): 118-125 (in Chinese)

Xie Wei (2004). Modularity and the emerging of China mobile phone manufacturing industry. Science and Technology Management Research, (4): 20-23 (in Chinese)

Xu H, Yan A, Pan X, Ma S (2005). Modular organization and corporate gene rebuilding. China Industrial Economy, (6): 52-59 (in Chinese)

Zhang Jun (2003). A Guide for the Chinese Version. In An Age of Modularity: the Nature of New Industrial Structure(ed. by Aoki M, Ando K), Shanghai Far East Publishers of China (in Chinese)

Zhang Ruimin (2007). Raising Haier. Harvard Business Review, 85(2): 141-146

Zhu Lin, Xu Qingrui, Wang Fangrui (2006). Transformation from the integration between R\&D and marketing to synergy between technological innovation and market innovation. Science Research Management, 27(5): 1-9 (in Chinese)

Zhu Ruibo (2004). Analysis on mechanism of resistance industry cluster's endogenous risk by modularity. China Industrial Economy, (5): 54-60 (in Chinese) 